\title{
MYCOВACTERIUM TUBERCULOSIS: ПРОБЛЕМЫ ЛЕКАРСТВЕННОЙ УСТОЙЧИВОСТИ, ВИРУЛЕНТНОСТИ И ПОДХОДЫ К ИХ РЕШЕНИЮ
}

\author{
В. Н. Даниленко ${ }^{1,2}$, М. В. Зайчикова 1 , И. Н. Дьяков ${ }^{3}$, К. В. Шур¹, Д. А. Маслов
}

1 Лаборатория генетики микроорганизмов, отдел генетических основ биотехнологии, Институт общей генетики имени Н. И. Вавилова, Москва

2 Научно-исследовательский центр биотехнологии антибиотиков «БИОАН», Москва

${ }^{3}$ Лаборатория биосинтеза иммуноглобулинов, Научно-исследовательский институт вакцин и сывороток имени И. И. Мечникова, Москва

\begin{abstract}
Несмотря на достигнутые успехи мероприятий, направленных на снижение смертности от туберкулеза, данное заболевание по прежнему крайне распространено, а в некоторых регионах России численность больных достигает показателей, характерных для уровня эпидемии. Многолетнее широкое применение антибиотиков, изменение состава микробиоты человека и ряд других факторов привели к появлению лекарственноустойчивых и высоковирулентных сублиний Mycobacterium tuberculosis. Недостаточность уровня и объема фундаментальных знаний о механизмах возникновения и формирования клонов $M$. tuberculosis, одновременно устойчивых ко многим антибиотикам и обладающих повышенной патогенностью, усложняет проблему и требует разработки новой концепции борьбы с туберкулезом. Ключевые понятия этой концепции - «суперорганизм», «микробиота» и «резистом». Возникновение форм с множественной (МЛУ) и широкой (ШЛУ) лекарственной устойчивостью следует рассматривать в контексте их формирования в составе некоторого суперорганизма, элементами которого являются собственно организм человека, его микробиота (в том числе влияющая на иммунный статус) и M. tuberculosis. Клинически тестируемые фенотипы и генотипы штаммов МЛУ/ШЛУ формируются на основе клональной изменчивости M. tuberculosis в “суперорганизме». Поэтому при разработке противотуберкулезных препаратов следует обращать особое внимание на создание вакцин, адъювантов и пробиотиков с селективными иммуномодулирующими и антиоксидантными свойствами.
\end{abstract}

Ключевые слова: туберкулез, Mycobacterium tuberculosis, лекарственная устойчивость, адъюванты, вакцины, перекрестная лекарственная устойчивость

Финансирование: работа была выполнена в рамках проекта Министерства образования и науки Российской Федерации №RFMEFI61317Х0068 «Роль регион-специфичных полиморфизмов генов вирулентности в формировании лекарственной устойчивости Mycobacterium tuberculosis».

$\bowtie$ Для корреспонденции: Валерий Николаевич Даниленко ул. Губкина, д. 3, г. Москва, 119991; valerid@vigg.ru

Статья получена: 05.06.2018 Статья принята к печати: 10.07.2018

DOI: $10.24075 /$ vrgmu.2018.038

\section{MYCOBACTERIUM TUBERCULOSIS: DRUG RESISTANCE, VIRULENCE AND POSSIBLE SOLUTIONS}

\author{
Danilenko VN ${ }^{1,2}$, Zaychikova MV1, Dyakov $\mathrm{IN}^{3}$, Shur KV11, Maslov DA ${ }^{1}$
}

${ }^{1}$ Laboratory of Bacterial Genetics, Department Genetics and Biotechnology, Vavilov Institute of General Genetics, Moscow

2 BIOAN Research Center for Biotechnology of Antibiotics, Moscow

${ }^{3}$ Laboratory of Immunoglobulin Biosynthesis, Mechnikov Research Institute of Vaccine and Sera, Moscow

In spite of successful measures taken to reduce mortality associated with tuberculosis, this disease is still widely spread. In some Russian regions the number of patients with tuberculosis is no short of the epidemic level. The long-term use of antibiotics, changes in the composition of the human microbiota and a few other factors have contributed to the emergence of drug-resistant and hypervirulent sublineages of Mycobacterium tuberculosis. Insufficient fundamental knowledge of mechanisms underlying the emergence and evolution of $M$. tuberculosis clones simultaneously resistant to a wide spectrum of antibiotics and exhibiting increased virulence complicates the situation and necessitates a new strategy to combat the disease. The key concepts of this strategy are «superorganism», «microbiota» and «resistome». The emergence of multidrugresistant (MDR) and extensively drug-resistant (XDR) strains should be addressed in the context of the "superorganism»; among its components are the human body, its microbiota (specifically, the bacteria that affect the immune status), and M. tuberculosis itself. Clinically studied phenotypes and genotypes of MDR/XDR strains are a result of clonal variability that M. tuberculosis develops as part of this «superorganism». Therefore, it is important to focus on the development of vaccines, adjuvants and probiotics with selective immunomodulating and antioxidant properties.

Keywords: tuberculosis, Mycobacterium tuberculosis, drug resistance, adjuvants, vaccines, cross-drug resistance

Funding: this work was supported by the Project of the Ministry of Education and Science of the Russian Federation «The role of region-specific polymorphisms of virulence genes in the formation of drug resistance of Mycobacterium tuberculosis» (Project ID RFMEFI61317X0068).

$\triangle$ Correspondence should be addressed: Valery N. Danilenko

Gubkina 3, Moscow, 119991; valerid@vigg.ru

Received: 05.06.2018 Accepted: 10.07.2018

DOI: $10.24075 /$ brsmu.2018.038 
В 2017 г. была принята Стратегия предупреждения распространения антимикробной резистентности в Российской Федерации на период до 2030 г, одной из задач которой является «Изучение механизмов возникновения антимикробной резистентности и разработка противомикробных препаратов и альтернативных методов, технологии и средств профилактики, диагностики и лечения инфекционных заболевании человека, животных и растении».

В настоящее время по оценкам Всемирной организации здравоохранения за 2016 г. туберкулез, возбудителем которого является Mycobacterium tuberculosis, является основной причиной смертности от инфекционных заболеваний (1,8 млн человек) и инфицирования (10,4млн человек) [1]. Основной проблемой, возникающей в борьбе с туберкулезом, является возникновение и распространение штаммов с множественной (МЛУ) и широкой (ШЛУ) лекарственной устойчивостью [2-4]. По статистике, МЛУ диагностируют в 4\% новых случаев инфицирования и у $21 \%$ ранее прошедших лечение пациентов, а в России эти показатели составляют 22 и 53\% соответственно. Разработка препаратов приводит к появлению новых механизмов резистентности. Помимо приобретенной, микобактерии обладают развитой системой природной лекарственной устойчивости, опосредованной наличием большого числа генов и генетических систем, объединенных в резистом. Концепция резистома была предложена в 2006 г. и подразумевает набор детерминант резистентности к антибиотикам, в том числе природную устойчивость, характерную для данного штамма бактерий, конкретного организма или экосистемы [5, 6]. Резистом M. tuberculosis включает гены, кодирующие белки различных классов: клеточные транспортеры, модификаторы мишеней и химической структуры лекарств, транскрипционные факторы ответа на стресс и ряд других.

Наряду с распространением лекарственноустойчивых форм большое значение имеет проблема возникновения сублиний бактерии M. tuberculosis, отличающихся повышенной вирулентностью [7-9]. Исследования с использованием лабораторных моделей in vitro (макросраги) и in vivo (мыши) выявили наличие корреляции между вирулентностью и принадлежностью возбудителя к определенному генотипу [10]. В подавляющем большинстве случаев повышенную вирулентность демонстрируют бактерии линии (генотипа) Beijing, имеющей наиболее важное эпидемиологическое значение ввиду все большего распространения в мире и высокой частоты возникновения лекарственноустойчивых форм [11, 12]. Штаммы линии Beijing отличаются генетической неоднородностью, что привело к выделению ряда сублиний. Хотя в целом линии Beijing свойственна повышенная частота возникновения форм с повышенной вирулентностью и лекарственной устойчивостью, эти характеристики варьируют в зависимости от сублинии $[13,14]$. Более того, различия в значимых с точки зрения клинической практики характеристиках могут наблюдаться даже у штаммов в составе одной сублинии.

Опыт последних десятилетий по изучению механизмов возникновения МЛУ/ШЛУ-фенотипа M. tuberculosis, создание активных в отношении таких штаммов антибиотиков, а также разработка просилактических и лечебных генно-инженерных вакцин и адъювантов к ним выявили ряд научных проблем [15]. Создание новых препаратов невозможно без понимания молекулярно-генетических механизмов возникновения и формирования лекарственной устойчивости и вирулентности.

\section{Проблема лекарственной устойчивости и разработка новых противотуберкулезных антибиотиков}

Помимо приобретенной лекарственной устойчивости существует природная лекарственная устойчивость, характеризующаяся низким (по сравнению с индуцированной) уровнем резистентности к антибиотикам. При воздействии антибактериального препарата на клетки M. tuberculosis у патогена активируются транскрипционные факторы, контролирующие экспрессию генов, чьи продукты способствуют модификации антибиотика или его мишени и обратному транспорту лекарственного вещества или его активных производных из бактериальной клетки. Гены, продукты экспрессии которых вовлечены в реализацию природной лекарственной устойчивости, служат мишенью для воздействия ряда факторов (включая сами антибиотики), что может приводить к изменению их экспрессии и, как следствие, к повышению уровня устойчивости бактерии.

Использование антибиотиков при лечении сопутствующих туберкулезу инфекционных заболеваний (или попадание антибиотиков в организм человека с продуктами питания) может способствовать повышению лекарственной устойчивости M. tuberculosis.

В 2015 г. пациентов, страдающих МЛУ- и ШЛУтуберкулезом, насчитывалось более 580000 человек. Столь широкое распространение эти штаммы получили в том числе из-за длительного применения одного и того же набора препаратов. Лишь недавно бедаквилин стал первым за последние 40 лет новым противотуберкулезным препаратом, применяемым в клинической практике [16].

В этой связи важной задачей становится разработка новых противотуберкулезных препаратов, к которым предъявляются следующие требования: высокая антимикобактериальная активность как в отношении лекарственно чувствительных штаммов M. tuberculosis, так и в отношении штаммов с МЛУ, а также специфичность к новой биомишени. На сегодняшний день разработкой новых противотуберкулезных препаратов, способных преодолеть феномен МЛУ/ШЛУ и/или сократить время противотуберкулезной химиотерапии, занимаются ведущие фармацевтические компании и исследовательские группы по всему миру, среди которых Lilly TB Drug Discovery Initiative, GSK, Roche, Sanofi, TB Alliance, Colorado State University и цельй ряд других (http://www.newtbdrugs.org).

В России работы по созданию противотуберкулезных препаратов активно велись в рамках программы «Фарма-2020». Так, в Институте общей генетики имени Н. И. Вавилова (Москва) совместно со специалистами по медицинской химии из ряда научных и коммерческих организаций (ИОС УрО РАН, ФГБНУ «НИИНА», ФГБУН НИОХ СО РАН, ИОХРАН, АНО «НИЦ «БИОАН», ООО «НовЫе научные технологии») были проведены и проводятся доклинические исследования противотуберкулезных препаратов новых химических классов: производных усниновой кислоты [17], замещенных азоло $(1,2,4,5)$ тетразинов [18], аминопиридинов и аминопиримидинов [19], производных аминопуринов [20].

C наступлением постгеномной эры поиск противотуберкулезных средств проводится по двум векторам: от мишени к препарату и от препарата к мишени [21-23].

На первый подход возлагались большие надежды, однако они не оправдались в полной мере. Многие препараты, показавшие высокие ингибирующие свойства in vitro в отношении фермента-мишени, не проявляли активности in vitro на M. tuberculosis из-за неспособности 
проникнуть сквозь микобактериальную клеточную стенку, либо не были активными на моделях in vivo вследствие того, что выбранная мишень уже не была жизненно важной в этих условиях [22, 24].

Из успешных опытов такого рода стоит отметить эксперимент по отбору соединения BDM31343, ингибитора EtHR, супрессора EthA, который, в свою очередь, активирует этионамид [25]. Препарат повышал чувствительность микобактерий к этионамиду и усиливал в три раза его действие в мышиных моделях [26].

В связи с низкой эффективностью такого подхода наметилась тенденция к возврату к более традиционному пути поиска: от препарата к мишени, основанному на клеточном отборе [24]. Этим путем были обнаружены все ныне используемые противотуберкулезные препараты, включая бедаквилин, претоманид, деламанид, Q203, SQ-109 и BTZ043 [27].

При таком подходе, зачастую, прибегают к высокопроизводительному отбору на бактериальных культурах штамма $M$. tuberculosis H37Rv, a также родственных ему модельных штаммах $M$. bovis BCG и M. smegmatis $[24,28]$. Поиск ведут на гигантских библиотеках химических соединений. Так, сотрудники компании GSK последовательным отбором на штаммах M. bovis BCG и $M$. tuberculosis H37Rv смогли отобрать из 2 млн соединений семь кандидатов в лекарства с высокой активностью, способностью проникать через клеточную стенку и низкой цитотоксичностью [29].

Подход «От препарата к мишени» сопряжен с необходимостью полногеномного секвенирования устойчивых к антибиотикам мутантов для обнаружения потенциальных биомишеней и проведения дальнейший исследований, направленных на подтверждение действия отобранных кандидатов в лекарственные препараты на эти потенциальные биомишени [24].

Глобальной задачей остается необходимость разработки препаратов, способных воздействовать на персистирующие формы M. tuberculosis. На сегодняшний день наиболее эффективным антибиотиком, способным поражать персистирующие клетки M. tuberculosis, является пиразинамид [30]. Устойчивость к пиразинамиду может сильно влиять на клинический прогноз, особенно в случае туберкулеза, вызванного МЛУ-формами бактерий [31, 32].

\section{Разработка противотуберкулезных вакцин}

Несмотря на то что вакцинация против возбудителя туберкулеза проводится повсеместно, заболеваемость остается аномально высокой. Это можно объяснить низкой эффективностью применяемой для глобальной иммунизации вакцины BCG (0-80\% в зависимости от возраста, иммунного статуса, региона проживания вакцинируемых и т. д.) [33]. На эффективность вакцины влияет и генетическое разнообразие патогена. Существует предположение, что снижение эффективности вакцинации в отношении повсеместно распространенных штаммов линии Beijing может являться одним из объяснений успешности данной группы [11]. На этом фоне создание новой противотуберкулезной вакцины относится к числу наиболее приоритетных исследований.

В настоящее время разработка противотуберкулезных вакцин ведется по двум направлениям. Первым из них является создание вакцин на основе непосредственно микроорганизма (аттенуированного), являющегося возбудителем этого заболевания. В качестве одного из подходов используется создание нокаутных по различным генам мутантов M. tuberculosis. В их число входят гены, кодирующие различные факторы вирулентности: белки Mce (mammalian cell entry), способствующие инвазии патогена; белки РPЕ; белки, участвующие в биосинтезе липидов; сигма-факторы; двухкомпонентные системы и ряд других.

Второе направление, по которому ведется разработка противотуберкулезных препаратов, основано на использовании субъединичных вакцин, содержащих антигены возбудителей, полученные с использованием методов генной инженерии $[34,35]$. К преимуществам таких вакцин относятся их высокая специфичность, меньшая аллергенность, простота производства и низкая себестоимость, удобство хранения и транспортировки [36].

В число белков - кандидатов для разработки вакцин нового поколения входят: секретируемые белки Ag85-комплекса, участвующие во взаимодействии с Т-лимфоцитами, ТВ10.4 (rv0288), Нsp65, белки РЕ и РPE. Наиболее перспективными кандидатами считают белки систем секреции ESAT6 и CFP [36].

Однако, несмотря на значительный интерес к данной проблематике, разработка генно-инженерных вакцин не оправдала надежд. Главным недостатком таких вакцин стала их низкая иммуногенность.

При разработке генно-инженерных вакцин ключевой задачей является поиск оптимальных антигенов [36]. Высокую антигенность демонстрируют структурные элементы патогенности, которых у M. tuberculosis насчитывается более 300, и часть из них выбрана в качестве основы для разработки субъединичных вакцин [37]. Для многих из этих генов характерно наличие однонуклеотидного полиморфизма, приводящего к замене аминокислоты; такая замена может оказывать влияние на структуру белка-продукта, изменяя антигенную активность. В настоящее время при производстве генно-инженерных вакцин внутривидовое разнообразие M. tuberculosis не учитывается. Как правило используют последовательность генов стандартного лабораторного штамма H37Rv. При этом в отношении используемого для изготовления вакцин штамма $M$. bovis BCG установлено, что возникновение мутаций (вследствие микроэволюции при длительном культивировании) влияет на эффективность вакцины [38]. Не исключено, что антигенная активность белков у разных штаммов M. tuberculosis также различна.

Еще одним перспективным направлением представляется разработка кандидатной мукозальной вакцины против туберкулеза, индуцирующей формирование в первую очередь местного мукозального иммунитета. Важность индукции местного противотуберкулезного иммунитета показана в ряде работ, в которых интраназальное введение защитных IgA, предварительная обработка вирулентных M. tuberculosis защитными IgA или же интраназальное введение $M$. bovis BCG приводило к формированию эффективного ответа на инфицирование M. tuberculosis [39-42]. Применение мукозальной вакцины (отдельно или вместе с подкожной формой), могло бы решить проблемы, возникающие при BCG-вакцинации.

Стоит отметить, что к настоящему моменту ни одна из упомянутых выше новых противотуберкулезных вакцин не применяется в клинической практике. Как уже было сказано, недостатком таких вакцин является низкая иммуногенность, что обусловливает необходимость использования в составе вакцинных препаратов иммуноадъювантов. 
Перспективы разработки адъювантов противотуберкулезных вакцин на основе штаммов пробиотиков

Под адъювантами подразумевают любые соединения, действующие неспецифично и повышающие иммунный ответ на вводимые вместе с ними антигены [43]. Из наиболее распространенных адъювантов можно выделить гидроксид алюминия и фосфат алюминия [44]. Однако для ряда антигенов адъювантный эффект этих соединений оказался недостаточным. K другим веществам, используемым в настоящее время в качестве адъювантов, можно отнести синтезируемый искусственно полиоксидоний и природный полисахарид хитозан. Кроме того, в качестве адъювантов испытывают различные компоненты клеток бактерий, которые содержат патогенассоциированные молекулярные паттерны (РАМР), запускающие иммунный ответ. В частности, описано адъювантное действие молочнокислых бактерий [45], компонентов бактериальной стенки [46, 47], ффибронектинсвязывающего белка 1 Streptococcus pyogenes [48], поверхностных флагеллинов [49] и других.

Отдельные штаммы пробиотиков, в частности бисидобактерий, способны запускать продукцию Th17- и Th1-цитокинов [50], играющих важную роль в мукозальном иммунном ответе при туберкулезной инфекции [39]. Таким образом, интраназальное введение пробиотиков может оказать адъювантный эффект в отношении мукозальной противотуберкулезной вакцины с формированием протективного иммунитета к вирулентным штаммам M. tuberculosis. Как представители комменсальной микрофлоры бифидобактерии и лактобациллы способны стимулировать механизмы иммунной защиты, влияя на секрецию и провоспалительных, и противовоспалительных цитокинов. При исследовании иммуномодулирующей активности штаммов бактерий in vitro, как правило, используют культуры клеток кишечника (Сасо-2, НТ-29) или иммуноцитов (ЕС-6, THP-1). In vivo подобные эксперименты проводят на лабораторных животных (здоровых, с дефектами иммунной системы, гнотобионтах, а также имеющих экспериментальную инфекционную и неинфекционную патологию) [51, 52].

Следует отметить, что разные штаммы бифидо- $и$ лактобацилл, а также их компоненты оказывают различный по степени выраженности иммуномодулирующий эффект [53-55]. Показано адъювантное действие лакто- и бифидобактерий при противовирусной вакцинации [56, 57], противострептококковой [58] и противоаллергической вакцинации $[48,59]$. Введенные интраназально лактобациллы повышали местный мукозальный иммунитет, а также влияли на системные механизмы иммунной защиты, повышая устойчивость к заражению респираторносинцитиальным вирусом [56, 57, 60] или вирусом гриппа. Представленные данные позволяют предположить, что применение интраназального введения пробиотиков в качестве адъювантов при вакцинации повысит эффективность формирования протективного мукозального иммунитета против M. tuberculosis.

\section{ЗАКЛЮЧЕНИЕ}

C момента появления человека M. tuberculosis присутствует в популяции как в активной, так и в латентной форме [61]. На примере штаммов линии Beijing, зародившейся на территории Китая около 7 тыс. лет назад и в настоящее время распространившейся по всему миру, можно наблюдать продолжающуюся эволюцию возбудителя туберкулеза через формирование новых молодых линий, таких как B0/W-148 (рис. 1) [62, 63].

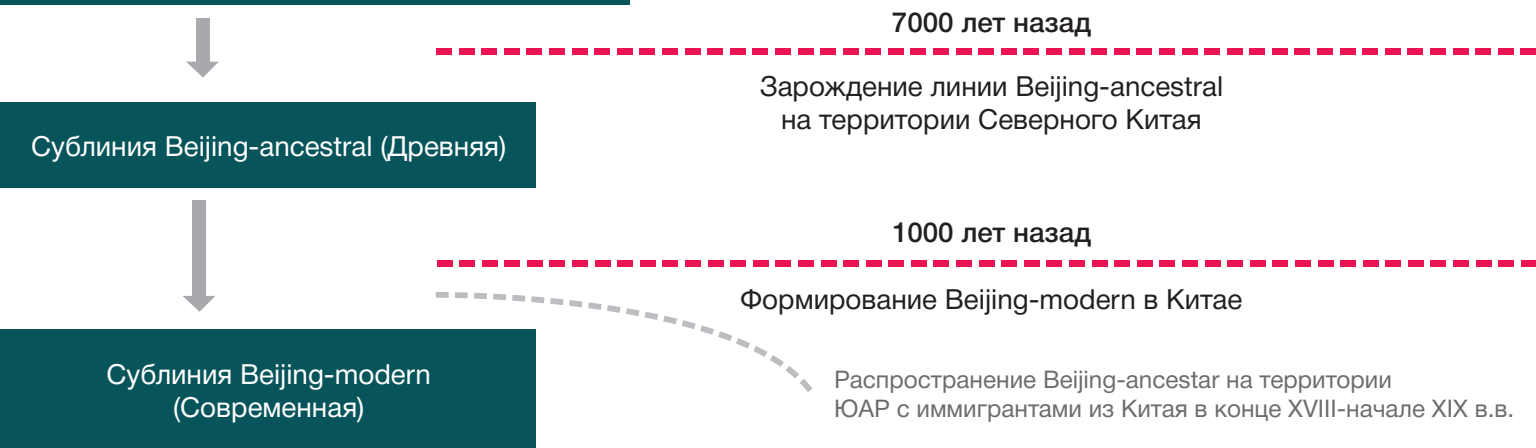

100 лет назад
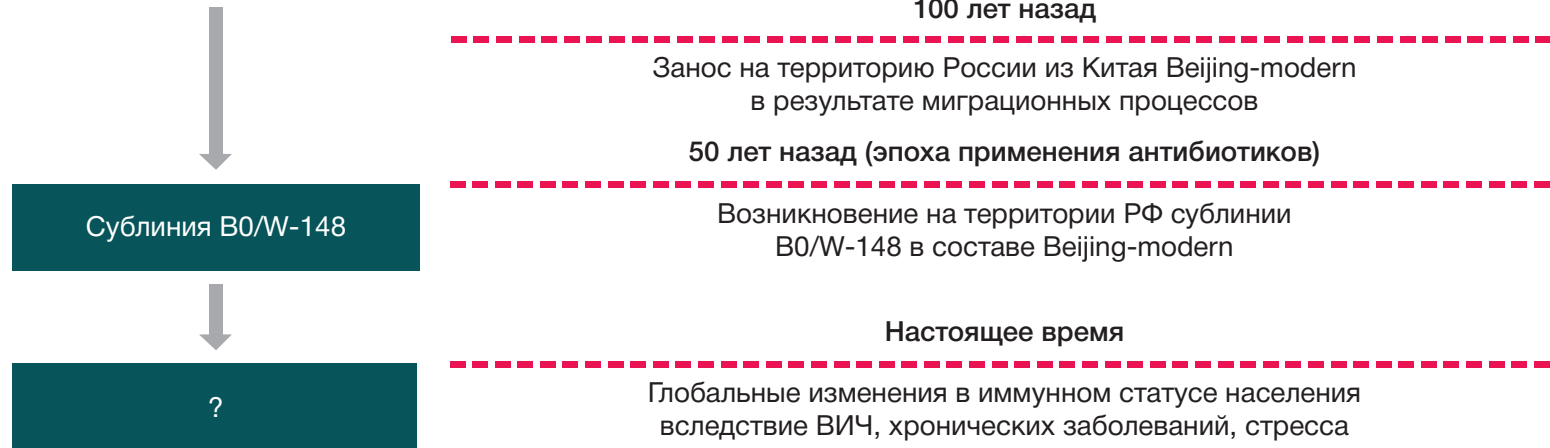

Глобальные изменения в иммунном статусе населения вследствие ВИЧ, хронических заболеваний, стресса

Рис. 1. Эволюция штаммов линии Beijing. Широкое применение антибиотиков в последние десятилетия обеспечило селективное преимущество клону B0/W-148, отличающемуся высоким уровнем лекарственной устойчивости 
Показано, что на восприимчивость к возбудителю туберкулеза влияет уровень экспресии различных генов в Т-лимфоцитах [64].

В связи с этим проблему формирования лекарственной устойчивости, увеличения вирулентности и разработки нового поколения противотуберкулезных препаратов следует рассматривать в контексте понятия «суперорганизм». Применение антибиотиков при противотуберкулезной терапии оказывает воздействие не только на патоген, но и на организм хозяина, что приводит, в числе прочего, к изменению состава кишечной микробиоты, и, как следствие, иммунитета, на который миробиота имеет непосредственное влияние. Прием антибиотиков влияет и на функционирование центральной и периферической нервных систем организма-хозяина, других систем и органов. Широкое применение антибиотиков в сельском хозяйстве ведет к их поступлению в продукты питания, что может приводить к формированию перекрестной лекарственной устойчивости. Кроме того, антибиотикотерапия при лечении микобактериозов может приводить к индукции латентного туберкулеза.

В целом можно констатировать, что основным фактором отбора при формировании лекарственноустойчивых вирулентноадаптированных форм M. tuberculosis в течение последних 60 лет является неконтролируемое применение антибиотиков. К числу других факторов можно отнести широкое распространение заболеваний, оказывающих влияние на иммунитет: ВИЧ, сахарный диабет 2-го типа, гепатит В и др. Определенное влияние оказывает изменение кишечной микробиоты, в связи со сменой диеты, усилением вследствии глобализации миграционных потоков и т. д. Генетическое разнообразие M. tuberculosis, обусловленное единичными нуклеотидными заменами (в первую очередь, в генах, определяющих вирулентность, природную лекарственную устойчивость, переход в персистирующее состояние), IS-элементами и, возможно, CRISPR-cas системами, тоже оказывает влияние на адаптацию патогена к организму хозяина $[65,66]$

Успехи в области эпидемиологии, молекулярной генетики, сравнительной геномики, протеомики и системной биологии, достигнутые за последние годы при изучении M. tuberculosis, приводят к пониманию многосракторности вызываемого им заболевания, и, как результат, к необходимости применения персонализированного подхода при лечении туберкулеза.

\section{Литература}

1. World Health Organization. Global tuberculosis report 2016 Доступно по ссылке: http://www.searo.who.int/tb/documents/ global-tuberculosis-report-2016/en/

2. Прозоров А. А., Зайчикова М. В., Даниленко В. Н. Мутанть Mycobacterium tuberculosis c множественной лекарственной устойчивостью: история появления, генетические и молекулярные механизмы устойчивости, возникающие проблемы. Генетика. 2012; 48 (1): 1-14

3. Dean AS, Cox H, Zignol M. Epidemiology of Drug-Resistant Tuberculosis. Adv Exp Med Biol. 2017; 1019: 209-20.

4. Lange C, Chesov D, Heyckendorf J, Leung CC, Udwadia Z, Dheda K. Drug-resistant tuberculosis: An update on disease burden, diagnosis and treatment. Respirology. 2018. DOI: 10.1111/resp.13304. [Epub ahead of print]

5. D'Costa VM, McGrann KM, Hughes DW, Wright GD. Sampling the antibiotic resistome. Science. 2006; 311 (5759): 374-7.

6. Wright GD. The antibiotic resistome: the nexus of chemical and genetic diversity. Nat Rev Microbiol. 2007; 5 (3): 175-86.

7. Mikheecheva NE, Zaychikova MV, Melerzanov AV, Danilenko VN. A nonsynonymous SNP catalog of Mycobacterium tuberculosis virulence genes and its use for detecting new potentially virulent sublineages. Genome Biol Evol. 2017; 9 (4): 887-99.

8. Zaychikova MV, Zakharevich NV, Sagaidak MO, Bogolubova NA, Smirnova TG, Andreevskaya SN, et al. Mycobacterium tuberculosis Type II Toxin-Antitoxin Systems: Genetic Polymorphisms and Functional Properties and the Possibility of Their Use for Genotyping. PLoS One. 2015; 10: e0143682.

9. Reiling N, Homolka S, Kohl TA, Steinhäuser C, Kolbe K, Schütze S, et al. Shaping the niche in macrophages: Genetic diversity of the M. tuberculosis complex and its consequences for the infected host. Int J Med Microbiol. 2017; pii: S1438-4221 (17) 30294-1.

10. Reiling N, Homolka S, Walter K, Brandenburg J, Niwinski L, Ernst M, et al. Clade specific virulence patterns of Mycobacterium tuberculosis complex strains in human primarymacrophages and aerogenically infected mice. MBio. 2013; e00250-13.

11. Hanekom M, Gey van Pittius NC, McEvoy C, Victor TC, Van Helden PD, Warren RM. Mycobacterium tuberculosis Beijing genotype: a template for success. Tuberculosis (Edinb). 2011; 91 (6): 510-23.

12. Zaychikova MV, Mikheecheva NE, Belay YO, Alekseeva MG Melerzanov AV, Danilenko VN. Single nucleotide polymorphisms of Beijing lineage Mycobacterium tuberculosis toxin-antitoxin system genes: their role in the changes of protein activity and evolution. Tuberculosis (Edinb). 2018; 112: 11-19.

13. Ebrahimi-Rad M, Bifani P, Martin C, Kremer K, Samper S, Rauzier J, et al. Mutations in putative mutator genes of Mycobacterium tuberculosis strains of the W-Beijing family. Emerg Infect Dis. 2003; 9 (7): 838-45.

14. Ribeiro SC, Gomes LL, Amaral EP, Andrade MR, Almeida FM, Rezende AL, et al. Mycobacterium tuberculosis strains of the modern sublineage of the Beijing family are more likely to display increased virulence than strains of the ancient sublineage. J Clin Microbiol. 2014; 52 (7): 2615-24.

15. Kaufmann SH, Evans TG, Hanekom WA. Tuberculosis vaccines: time for a global strategy. Sci Transl Med. 2015; 7 (276): 276fs8.

16. Chahine EB, Karaoui LR, Mansour H. Bedaquiline: a novel diarylquinoline for multidrug-resistant tuberculosis. Ann Pharmacother. 2014; 48 (1): 107-15.

17. Bekker OB, Sokolov DN, Luzina OA, Komarova NI, Gatilov YV, Andreevskaya SN, et al. Synthesis and activity of (+)-usnic acid and (-)-usnic acid derivatives containing 1,3-thiazole cycle against Mycobacterium tuberculosis. Med Chem Res. 2015; 24 (7): 2926-38.

18. Маслов Д. А., Беккер О. Б., Даниленко В. Н. Тест-система Mycobacterium smegmatis aphVIII+ для скрининга ингибиторов серин-треониновых протеинкиназ эукариотического типа. Патент РФ № 2566998, от 27.10.2015.

19. Маслов Д. А., Беккер О. Б., Алексеева М. Г., Князева Л. М., Мавлетова Д. А., Афанасьев И. И., и др. Ингибиторы серинтреониновых протеинкиназ классов аминопиридинов и аминопиримидинов - кандидаты в препараты для лечения лекарственноустойчивых форм туберкулеза. Вестник РГМУ. 2017; 1: 42-7.

20. Krasnov VP, Vigorov AY, Musiyak W, Nizova IA, Gruzdev DA, Matveeva TV, et al. Synthesis and antimycobacterial activity of $\mathrm{N}$-(2-aminopurin-6-yl) and $\mathrm{N}$-(purin-6-yl) amino acids and dipeptides Bioorg Med Chem Lett. 2016; 26 (11): 2645-8.

21. Sala C, Hartkoorn RC. Tuberculosis drugs: new candidates and how to find more. Future Microbiol. 2011; 6 (6): 617-33.

22. Lechartier B, Rybniker J, Zumla A, Cole ST. Tuberculosis drug discovery in the post-post-genomic era. EMBO Mol Med. 2014; 6 (2): 158-68.

23. Danilenko VN, Osolodkin DI, Lakatosh SA, Preobrazhenskaya MN, Shtil AA. Bacterial eukaryotic type serine-threonine protein 
kinases: from structural biology to targeted anti-infective drug design. Curr Top Med Chem. 2011; 11 (11): 1352-69.

24. Cooper CB. Development of Mycobacterium tuberculosis whole cell screening hits as potential antituberculosis agents. J Med Chem. 2013; 56 (20): 7755-60.

25. Baulard AR, Betts JC, Engohang-Ndong J, Quan S, McAdam RA, Brennan PJ, et al. Activation of the pro-drug ethionamide is regulated in mycobacteria. J Biol Chem. 2000; 275 (36): 2832631.

26. Willand N, Dirié B, Carette X, Bifani $P$, Singhal A, Desroses M, et al. Synthetic EthR inhibitors boost antituberculous activity of ethionamide. Nat Med. 2009; 15 (5): 537-44.

27. Andries K, Verhasselt P, Guillemont J, Göhlmann HW, Neefs JM, Winkler $\mathrm{H}$, et al. A diarylquinoline drug active on the ATP synthase of Mycobacterium tuberculosis. Science. 2005; 307 (5707): 223-7.

28. Ananthan S, Faaleolea ER, Goldman RC, Hobrath JV, Kwong CD, Laughon BE, et al. High-throughput screening for inhibitors of Mycobacterium tuberculosis H37Rv. Tuberculosis (Edinb). 2009; 89 (5): 334-53.

29. Ballell L, Bates RH, Young RJ, Alvarez-Gomez D, Alvarez-Ruiz E, Barroso V, et al. Fueling open-source drug discovery: 177 smallmolecule leads against tuberculosis. Chem Med Chem. 2013; 8 (2): 313-21.

30. Zhang Y, Mitchison D. The curious characteristics of pyrazinamide: a review. Int J Tuberc Lung Dis. 2003; 7 (1): 6-21.

31. Zhang Y, Chiu Chang K, Leung C-C, Wai Yew W, Gicquel B, Fallows D, et al. 'ZS-MDR-TB' versus 'ZR-MDR-TB': improving treatment of MDR-TB by identifying pyrazinamide susceptibility. Emerg Microbes Infect. 2012; 1 (7): e5.

32. Maslov DA, Zaĭchikova MV, Chernousova LN, Shur KV, Bekker OB, Smirnova TG, et al. Resistance to pyrazinamide in Russian Mycobacterium tuberculosis isolates: pncA sequencing versus Bactec MGIT 960. Tuberculosis (Edinb). 2015; 95 (5): $608-12$

33. Mangtani P, Abubakar I, Ariti C, Beynon R, Pimpin L, Fine PE, et al. Protection by BCG vaccine against tuberculosis: a systematic review of randomized controlled trials. Clin Infect Dis. 2014; 58 (4): 470-80.

34. Kaufmann SH, Weiner J, von Reyn CF. Novel approaches to tuberculosis vaccine development. Int $\mathrm{J}$ Infect Dis. 2017; 56: 263-7.

35. Méndez-Samperio P. Global Efforts in the Development of Vaccines for Tuberculosis: Requirements for Improved Vaccines Against Mycobacterium tuberculosis. Scand J Immunol. 2016; 84 (4): 204-10.

36. Andersen $\mathrm{P}$, Kaufmann $\mathrm{SH}$. Novel vaccination strategies against tuberculosis. Cold Spring Harb Perspect Med. 2014; 4 (6). pii: a018523.

37. Forrellad MA, Klepp L, Gioffré A, Sabioy García J, Morbidoni HR, de la Paz Santangelo $M$, et al. Virulence factors of the Mycobacterium tuberculosis complex. Virulence. 2013; 4 (1): 3-66.

38. Brosch R, Gordon SV, Garnier T, Eiglmeier K, Frigui W, Valenti P, et al. Genome plasticity of BCG and impact on vaccine efficacy. Proc Natl Acad Sci USA. 2007; 104 (13): 5596-601.

39. Uranga S, Marinova D, Martin C, Aguilo N. Protective Efficacy and Pulmonary Immune Response Following Subcutaneous and Intranasal BCG Administration in Mice. J Vis Exp. 2016; 115. DOI: $10.3791 / 54440$

40. Zimmermann N, Thormann V, Hu B, Köhler AB, Imai-Matsushima A, Locht $\mathrm{C}$, et al. Human isotype-dependent inhibitory antibody responses against Mycobacterium tuberculosis. EMBO Mol Med. 2016; 8 (11): 1325-39.

41. Alvarez N, Infante JF, Borrero R, Mata D, Payan JB, Hossain MM, et al. Histopathological Study of the Lungs of Mice Receiving Human Secretory IgA and Challenged with Mycobacterium tuberculosis. Malays J Med Sci. 2014; 21 (3): 31-7.

42. Alvarez N, Otero O, Camacho F, Borrero R, Tirado Y, Puig A, et al. Passive administration of purified secretory IgA from human colostrum induces protection against Mycobacterium tuberculosis in a murine model of progressive pulmonary infection. BMC Immunol. 2013; 14 (Suppl 1): S3.

43. Savelkoul HFJ, Ferro VA, Strioga MM, Schijns VEJ.C. Choice and Design of Adjuvants for Parenteral and Mucosal Vaccines. Vaccines (Basel). 2015; 3 (1): 148-71.

44. Edelman R. Vaccine adjuvants. Rev Infect Dis. 1980; 2 (3): 370-83.

45. Pouwels PH, Leer RJ, Shaw M, Heijne den Bak-Glashouwer MJ, Tielen FD, Smit E, et al. Lactic acid bacteria as antigen delivery vehicles for oral immunization purposes. Int J Food Microbiol. 1998; 41 (2): 155-67.

46. Bessler WG, Huber M, Baier W. Bacterial cell wall components as immunomodulators-II. The bacterial cell wall extract OM-85 $\mathrm{BV}$ as unspecific activator, immunogen and adjuvant in mice Int $J$ Immunopharmacol. 1997; 19 (9-10): 551-8.

47. López P, González-Rodríguez I, Sánchez B, Gueimonde M, Margolles A, Suárez A. Treg-inducing membrane vesicles from Bifidobacterium bifidum LMG13195 as potential adjuvants in immunotherapy. Vaccine. 2012; 30 (5): 825-9.

48. Medina E, Talay SR, Chhatwal GS, Guzmán CA. Fibronectinbinding protein I of Streptococcus pyogenes is a promising adjuvant for antigens delivered by mucosal route. Eur $\mathrm{J}$ Immunol. 1998: 28 (3): 1069-77.

49. Mizel SB, Bates JT. Flagellin as an adjuvant: cellular mechanisms and potential. J Immunol. 2010; 185 (10): 5677-82.

50. López P, Gueimonde M, Margolles A, Suárez A. Distinct Bifidobacterium strains drive different immune responses in vitro. Int J Food Microbiol. 2010; 138 (1-2): 157-65.

51. Caselli M, Vaira D, Cassol F, Calò G. Recombinant probiotics and their potential in human health. Int $\mathrm{J}$ Probiotics \& Prebiotics. 2012; 7 (2): 53-8

52. Федорова И. А., Даниленко В. Н. Иммуногенные свойства пробиотического компонента микробиоты желудочнокишечного тракта. Успехи современной биологии. 2014; 134 (2): 99-110.

53. Medina M, Izquierdo E, Ennahar S, Sanz Y. Differential immunomodulatory properties of Bifidobacterium logum strains: relevance to probiotic selection and clinical applications. Clin Exp Immunol. 2007 Dec; 150 (3): 531-8.

54. Khokhlova EV, Smeianov W, Efimov BA, Kafarskaia LI, Pavlova SI, Shkoporov AN. Anti-inflammatory properties of intestinal Bifidobacterium strains isolated from healthy infants. Microbiol Immunol. 2012 Jan; 56 (1): 27-39.

55. Аверина О. В., Ермоленко Е. И., Ратушный А. Ю., Тарасова Е. А., Борщев Ю. Ю., Леонтьева Г. Ф., и др. Влияние пробиотиков на продукцию цитокинов в системах in vitro $n$ in vivo. Медицинская иммунология. 2015; 17 (5): 443-54.

56. Barbieri N, Villena J, Herrera M, Salva S, Alvarez S. Nasally administered Lactobacillus rhamnosus accelerate the recovery of humoral immunity in B lymphocyte-deficient malnourished mice. J Nutr. 2013; Feb; 143 (2): 227-35.

57. Tomosada Y, Chiba E, Zelaya H, Takahashi T, Tsukida K, Kitazawa H, et al. Nasally administered Lactobacillus rhamnosus strains differentially modulate respiratory antiviral immune responses and induce protection against respiratory syncytial virus infection. BMC Immunol. 2013 Aug; 15 (14): 40.

58. Леонтьева Г. Ф., Крамская Т. А., Грабовская К. Б., Филимонова В. Ю., Лайно Д., Виллена Д., и др. Использование лактобацилл в качестве адъювантов при интраназальной иммунизации химерной пневмококковой вакциной. Медицинская иммунология. 2016; 18 (6): 545-54.

59. Van Overtvelt L, Moussu H, Horiot S, Samson S, Lombardi V, Mascarell $\mathrm{L}$, et al. Lactic acid bacteria as adjuvants for sublingual allergy vaccines. Vaccine. 2010 Apr 9; 28 (17): 2986-92.

60. Harata G, He F, Hiruta N, Kawase M, Kubota A, Hiramatsu M, et al. Intranasally administered Lactobacillusgasseri TMC0356 protects mice from $\mathrm{H} 1 \mathrm{~N} 1$ influenza virus infection by stimulating respiratory immune responses. World J Microbiol Biotechnol. 2011; 27 (2): 411-16.

61. Gagneux S. Ecology and evolution of Mycobacterium tuberculosis. Nat Rev Microbiol. 2018 Apr; 16 (4): 202-13.

62. Merker M, Blin C, Mona S, Duforet-Frebourg N, Lecher S, Willery $E$, et al. Evolutionary history and global spread of the Mycobacterium tuberculosis Beijing lineage. Nat Genet. 2015; 47 (3): 242-9.

63. Mokrousov I. Insights into the Origin, Emergence, and Current Spread of a Successful Russian Clone of Mycobacterium 
tuberculosis. Clin Microbiol Rev. 2013; 26 (2): 342-60.

64. Lyadova IV, Eruslanov EB, Khaidukov SV, Yeremeev W, Majorov KB, et al. Comparative analysis of $\mathrm{T}$ lymphocytes recovered from the lungs of mice genetically susceptible, resistant, and hyperresistant to Mycobacterium tuberculosis-triggered disease. J Immunol. 2000 Nov 15; 165 (10): 5921-31.

65. Зайчикова М. В., Захаревич Н. В., Чекалина М. С., Даниленко В. Н. CRISPR-Cas системы Mycobacterium tuberculosis: структура модуля, изменение в процессе эволюции у различных линий, возможная роль в формировании вирулентности и лекарственной устойчивости. Вестник РГМУ. 2018; 2: 5-14. DOI: 10.24075/ vrgmu.2018.015

66. Shitikov E, Bespyatykh J, Ischenko D, Alexeev D, Karpova I, Kostryukova E, et al. Unusual Large-Scale Chromosomal Rearrangements in Mycobacterium tuberculosis Beijing B0/W148 Cluster Isolates. PLoS One. 2014; 9 (1): e84971.

\section{References}

1. World Health Organization. Global tuberculosis report 2016. Available from: http://www.searo.who.int/tb/documents/globaltuberculosis-report-2016/en/

2. Prozorov AA, Zaichikova MV, Danilenko VN. Mycobacterium tuberculosis mutants with multidrug resistance: History of origin, genetic and molecular mechanisms of resistance, and emerging challenges. Russian Journal of Genetics. 2012; 48 (1): 1-14.

3. Dean AS, Cox H, Zignol M. Epidemiology of Drug-Resistant Tuberculosis. Adv Exp Med Biol. 2017; 1019: 209-20.

4. Lange C, Chesov D, Heyckendorf J, Leung CC, Udwadia Z, Dheda K. Drug-resistant tuberculosis: An update on disease burden, diagnosis and treatment. Respirology. 2018. DOI: 10.1111/resp.13304. [Epub ahead of print]

5. D'Costa VM, McGrann KM, Hughes DW, Wright GD. Sampling the antibiotic resistome. Science. 2006; 311 (5759): 374-7.

6. Wright GD. The antibiotic resistome: the nexus of chemical and genetic diversity. Nat Rev Microbiol. 2007; 5 (3): 175-86.

7. Mikheecheva NE, Zaychikova MV, Melerzanov AV, Danilenko VN. A nonsynonymous SNP catalog of Mycobacterium tuberculosis virulence genes and its use for detecting new potentially virulent sublineages. Genome Biol Evol. 2017; 9 (4): 887-99.

8. Zaychikova MV, Zakharevich NV, Sagaidak MO, Bogolubova NA Smirnova TG, Andreevskaya SN, et al. Mycobacterium tuberculosis Type II Toxin-Antitoxin Systems: Genetic Polymorphisms and Functional Properties and the Possibility of Their Use for Genotyping. PLoS One. 2015; 10: e0143682.

9. Reiling N, Homolka S, Kohl TA, Steinhäuser C, Kolbe K, Schütze S, et al. Shaping the niche in macrophages: Genetic diversity of the M. tuberculosis complex and its consequences for the infected host. Int J Med Microbiol. 2017; pii: S1438-4221 (17) 30294-1.

10. Reiling N, Homolka S, Walter K, Brandenburg J, Niwinski L, Ernst M, et al. Clade specific virulence patterns of Mycobacterium tuberculosis complex strains in human primarymacrophages and aerogenically infected mice. MBio. 2013; e00250-13.

11. Hanekom M, Gey van Pittius NC, McEvoy C, Victor TC, Van Helden PD, Warren RM. Mycobacterium tuberculosis Beijing genotype: a template for success. Tuberculosis (Edinb). 2011; 91 (6): 510-23.

12. Zaychikova MV, Mikheecheva NE, Belay YO, Alekseeva MG Melerzanov AV, Danilenko VN. Single nucleotide polymorphisms of Beijing lineage Mycobacterium tuberculosis toxin-antitoxin system genes: their role in the changes of protein activity and evolution. Tuberculosis (Edinb). 2018; 112: 11-19.

13. Ebrahimi-Rad M, Bifani P, Martin C, Kremer K, Samper S, Rauzier J, et al. Mutations in putative mutator genes of Mycobacterium tuberculosis strains of the W-Beijing family. Emerg Infect Dis. 2003; 9 (7): 838-45.

14. Ribeiro SC, Gomes LL, Amaral EP, Andrade MR, Almeida FM, Rezende $\mathrm{AL}$, et al. Mycobacterium tuberculosis strains of the modern sublineage of the Beijing family are more likely to display increased virulence than strains of the ancient sublineage. J Clin Microbiol. 2014; 52 (7): 2615-24.

15. Kaufmann SH, Evans TG, Hanekom WA. Tuberculosis vaccines: time for a global strategy. Sci Transl Med. 2015; 7 (276): 276 fs8.

16. Chahine EB, Karaoui LR, Mansour $H$. Bedaquiline: a novel diarylquinoline for multidrug-resistant tuberculosis. Ann Pharmacother. 2014; 48 (1): 107-15.

17. Bekker OB, Sokolov DN, Luzina OA, Komarova NI, Gatilov YV, Andreevskaya SN, et al. Synthesis and activity of (+)-usnic acid and (-)-usnic acid derivatives containing 1,3-thiazole cycle against

Mycobacterium tuberculosis. Med Chem Res. 2015; 24 (7): 2926-38.

18. Maslov DA, Bekker OB, Danilenko VN. New Test System for Serine/Threonine Protein Kinase Inhibitors Screening. Patent RF № 2566998, 27.10.2015.

19. Maslov DA, Bekker OB, Alekseeva MG, Kniazeva LM, Mavletova DA, Afanasyev II, et al. Aminopyridine- and aminopyrimidine-based serine/threonine protein kinase inhibitors are drug candidates for treating drug-resistant tuberculosis. Bulletin of Russian State Medical University. 2017; 1: 38-43.

20. Krasnov VP, Vigorov AY, Musiyak W, Nizova IA, Gruzdev DA, Matveeva TV, et al. Synthesis and antimycobacterial activity of $\mathrm{N}$-(2-aminopurin-6-yl) and $\mathrm{N}$-(purin-6-yl) amino acids and dipeptides Bioorg Med Chem Lett. 2016; 26 (11): 2645-8.

21. Sala C, Hartkoorn RC. Tuberculosis drugs: new candidates and how to find more. Future Microbiol. 2011; 6 (6): 617-33.

22. Lechartier B, Rybniker J, Zumla A, Cole ST. Tuberculosis drug discovery in the post-post-genomic era. EMBO Mol Med. 2014; 6 (2): 158-68

23. Danilenko VN, Osolodkin DI, Lakatosh SA, Preobrazhenskaya MN, Shtil AA. Bacterial eukaryotic type serine-threonine protein kinases: from structural biology to targeted anti-infective drug design. Curr Top Med Chem. 2011; 11 (11): 1352-69.

24. Cooper CB. Development of Mycobacterium tuberculosis whole cell screening hits as potential antituberculosis agents. J Med Chem. 2013; 56 (20): 7755-60.

25. Baulard AR, Betts JC, Engohang-Ndong J, Quan S, McAdam RA, Brennan PJ, et al. Activation of the pro-drug ethionamide is regulated in mycobacteria. J Biol Chem. 2000; 275 (36): 28326-31.

26. Willand N, Dirié B, Carette X, Bifani P, Singhal A, Desroses M, et al. Synthetic EthR inhibitors boost antituberculous activity of ethionamide. Nat Med. 2009; 15 (5): 537-44.

27. Andries K, Verhasselt P, Guillemont J, Göhlmann HW, Neefs JM, Winkler $\mathrm{H}$, et al. A diarylquinoline drug active on the ATP synthase of Mycobacterium tuberculosis. Science. 2005; 307 (5707): 2237 .

28. Ananthan S, Faaleolea ER, Goldman RC, Hobrath JV, Kwong CD, Laughon BE, et al. High-throughput screening for inhibitors of Mycobacterium tuberculosis H37Rv. Tuberculosis (Edinb). 2009; 89 (5): 334-53.

29. Ballell L, Bates RH, Young RJ, Alvarez-Gomez D, Alvarez-Ruiz E, Barroso V, et al. Fueling open-source drug discovery: 177 smallmolecule leads against tuberculosis. Chem Med Chem. 2013; 8 (2): 313-21.

30. Zhang Y, Mitchison D. The curious characteristics of pyrazinamide: a review. Int J Tuberc Lung Dis. 2003; 7 (1): 6-21.

31. Zhang Y, Chiu Chang K, Leung C-C, Wai Yew W, Gicquel B Fallows D, et al. 'ZS-MDR-TB' versus 'ZR-MDR-TB': improving treatment of MDR-TB by identifying pyrazinamide susceptibility. Emerg Microbes Infect. 2012; 1 (7): e5.

32. Maslov DA, Zaĭchikova MV, Chernousova LN, Shur KV, Bekker OB, Smirnova TG, et al. Resistance to pyrazinamide in Russian Mycobacterium tuberculosis isolates: pncA sequencing versus Bactec MGIT 960. Tuberculosis (Edinb). 2015; 95 (5): 608-12.

33. Mangtani P, Abubakar I, Ariti C, Beynon R, Pimpin L, Fine PE, et al. Protection by BCG vaccine against tuberculosis: a systematic review of randomized controlled trials. Clin Infect Dis. 2014; 58 (4): 470-80.

34. Kaufmann SH, Weiner J, von Reyn CF. Novel approaches to 
tuberculosis vaccine development. Int J Infect Dis. 2017; 56: 263-7.

35. Méndez-Samperio P. Global Efforts in the Development of Vaccines for Tuberculosis: Requirements for Improved Vaccines Against Mycobacterium tuberculosis. Scand J Immunol. 2016; 84 (4): 204-10.

36. Andersen P, Kaufmann SH. Novel vaccination strategies against tuberculosis. Cold Spring Harb Perspect Med. 2014; 4 (6). pii: a018523.

37. Forrellad MA, Klepp L, Gioffré A, Sabioy García J, Morbidoni HR, de la Paz Santangelo M, et al. Virulence factors of the Mycobacterium tuberculosis complex. Virulence. 2013; 4 (1): 3-66.

38. Brosch R, Gordon SV, Garnier T, Eiglmeier K, Frigui W, Valenti P et al. Genome plasticity of BCG and impact on vaccine efficacy. Proc Natl Acad Sci USA. 2007; 104 (13): 5596-601.

39. Uranga S, Marinova D, Martin C, Aguilo N. Protective Efficacy and Pulmonary Immune Response Following Subcutaneous and Intranasal BCG Administration in Mice. J Vis Exp. 2016; 115. DOI: 10.3791/54440.

40. Zimmermann N, Thormann V, Hu B, Köhler AB, Imai-Matsushima A Locht $\mathrm{C}$, et al. Human isotype-dependent inhibitory antibody responses against Mycobacterium tuberculosis. EMBO Mol Med. 2016; 8 (11): 1325-39

41. Alvarez N, Infante JF, Borrero R, Mata D, Payan JB, Hossain MM, et al. Histopathological Study of the Lungs of Mice Receiving Human Secretory IgA and Challenged with Mycobacterium tuberculosis. Malays J Med Sci. 2014; 21 (3): 31-7.

42. Alvarez N, Otero O, Camacho F, Borrero R, Tirado Y, Puig A, et al. Passive administration of purified secretory IgA from human colostrum induces protection against Mycobacterium tuberculosis in a murine model of progressive pulmonary infection. BMC Immunol. 2013; 14 (Suppl 1): S3.

43. Savelkoul HFJ, Ferro VA, Strioga MM, Schijns VEJ.C. Choice and Design of Adjuvants for Parenteral and Mucosal Vaccines. Vaccines (Basel). 2015; 3 (1): 148-71.

44. Edelman R. Vaccine adjuvants. Rev Infect Dis. 1980; 2 (3): 370-83.

45. Pouwels PH, Leer RJ, Shaw M, Heijne den Bak-Glashouwer MJ, Tielen FD, Smit E, et al. Lactic acid bacteria as antigen delivery vehicles for oral immunization purposes. Int J Food Microbiol. 1998; 41 (2): 155-67.

46. Bessler WG, Huber M, Baier W. Bacterial cell wall components as immunomodulators-II. The bacterial cell wall extract OM-85 BV as unspecific activator, immunogen and adjuvant in mice Int $J$ Immunopharmacol. 1997: 19 (9-10): 551-8.

47. López P, González-Rodríguez I, Sánchez B, Gueimonde M, Margolles A, Suárez A. Treg-inducing membrane vesicles from Bifidobacterium bifidum LMG13195 as potential adjuvants in immunotherapy. Vaccine. 2012; 30 (5): 825-9.

48. Medina E, Talay SR, Chhatwal GS, Guzmán CA. Fibronectinbinding protein I of Streptococcus pyogenes is a promising adjuvant for antigens delivered by mucosal route. Eur J Immunol. 1998; 28 (3): 1069-77.

49. Mizel SB, Bates JT. Flagellin as an adjuvant: cellular mechanisms and potential. J Immunol. 2010; 185 (10): 5677-82.

50. López P, Gueimonde M, Margolles A, Suárez A. Distinct Bifidobacterium strains drive different immune responses in vitro. Int J Food Microbiol. 2010; 138 (1-2): 157-65.

51. Caselli M, Vaira D, Cassol F, Calò G. Recombinant probiotics and their potential in human health. Int $\mathrm{J}$ Probiotics \& Prebiotics. 2012; 7 (2): 53-8.
52. Fedorova IA, Danilenko VN. Immunogenic properties of the probiotic component of the microbiota of the gastrointestinal tract. Biology Bulletin Reviews. 2014; 134 (2): 99-110.

53. Medina M, Izquierdo E, Ennahar S, Sanz Y. Differential immunomodulatory properties of Bifidobacterium logum strains: relevance to probiotic selection and clinical applications. Clin Exp Immunol. 2007 Dec; 150 (3): 531-8.

54. Khokhlova EV, Smeianov W, Efimov BA, Kafarskaia LI, Pavlova SI, Shkoporov AN. Anti-inflammatory properties of intestinal Bifidobacterium strains isolated from healthy infants. Microbiol Immunol. 2012 Jan; 56 (1): 27-39.

55. Averina OV, Ermolenko El, Ratushniy AYu, Tarasova EA, Borschev YuYu, Leontieva G F, i dr. Vlijanie probiotikov na produkciju citokinov v sistemah in vitro i in vivo. Medicinskaja immunologija. 2015; 17 (5): 443-54.

56. Barbieri N, Villena J, Herrera M, Salva S, Alvarez S. Nasally administered Lactobacillus rhamnosus accelerate the recovery of humoral immunity in B lymphocyte-deficient malnourished mice. J Nutr. 2013 Feb; 143 (2): 227-35.

57. Tomosada Y, Chiba E, Zelaya H, Takahashi T, Tsukida K, Kitazawa H, et al. Nasally administered Lactobacillus rhamnosus strains differentially modulate respiratory antiviral immune responses and induce protection against respiratory syncytial virus infection. BMC Immunol. 2013 Aug; 15 (14): 40

58. Leontieva GF, Kramskaya TA, Grabovskaya KB, Philimonova VY, Layno D, Villena D, i dr. Ispol'zovanie laktobacill $\vee$ kachestve ad"juvantov pri intranazal'noj immunizacii himernoj pnevmokokkovoj vakcinoj. Medicinskaja immunologija. 2016; 18 (6): 545-54.

59. Van Overtvelt L, Moussu H, Horiot S, Samson S, Lombardi V, Mascarell L, et al. Lactic acid bacteria as adjuvants for sublingual allergy vaccines. Vaccine. 2010 Apr 9; 28 (17): 2986-92.

60. Harata G, He F, Hiruta N, Kawase M, Kubota A, Hiramatsu M, et al. Intranasally administered Lactobacillusgasseri TMC0356 protects mice from $\mathrm{H} 1 \mathrm{~N} 1$ influenza virus infection by stimulating respiratory immune responses. World J Microbiol Biotechnol. 2011; 27 (2): 411-16.

61. Gagneux S. Ecology and evolution of Mycobacterium tuberculosis. Nat Rev Microbiol. 2018 Apr; 16 (4): 202-13.

62. Merker M, Blin C, Mona S, Duforet-Frebourg N, Lecher S, Willery $\mathrm{E}$, et al. Evolutionary history and global spread of the Mycobacterium tuberculosis Beijing lineage. Nat Genet. 2015; 47 (3): 242-9.

63. Mokrousov I. Insights into the Origin, Emergence, and Current Spread of a Successful Russian Clone of Mycobacterium tuberculosis. Clin Microbiol Rev. 2013; 26 (2): 342-60.

64. Lyadova IV, Eruslanov EB, Khaidukov SV, Yeremeev W, Majorov KB, et al. Comparative analysis of $\mathrm{T}$ lymphocytes recovered from the lungs of mice genetically susceptible, resistant, and hyperresistant to Mycobacterium tuberculosis-triggered disease. J Immunol. 2000 Nov 15; 165 (10): 5921-31.

65. Zaychikova MV, Zakharevich NV, Chekalina MS, Danilenko VN CRISPR-Cas systems of Mycobacterium tuberculosis: the structure, evolutionary changes in different lineages, and a possible role in the promotion of virulence and resistance to drugs. Bulletin of Russian State Medical University. 2018; 2: 5-14. DOI: 10.24075/vrgmu.2018.015.

66. Shitikov E, Bespyatykh J, Ischenko D, Alexeev D, Karpova I, Kostryukova E, et al. Unusual Large-Scale Chromosomal Rearrangements in Mycobacterium tuberculosis Beijing B0/W148 Cluster Isolates. PLoS One. 2014; 9 (1): e84971. 